\title{
BI-RADS Classification for Management of Abnormal Mammograms
}

\author{
Margaret M. Eberl, MD, MPH, Chester H. Fox, MD, Stephen B. Edge, MD, \\ Catbleen A. Carter, PhD, and Martin C. Maboney, MD, PhD, FAAFP
}

The Breast Imaging Reporting and Data System (BI-RADS), developed by the American College of Radiology, provides a standardized classification for mammographic studies. This system demonstrates good correlation with the likelihood of breast malignancy. The BI-RADS system can inform family physicians about key findings, identify appropriate follow-up and management and encourage the provision of educational and emotional support to patients. (J Am Board Fam Med 2006;19:161-4.)

The Breast Imaging Reporting and Data System (BI-RADS) was developed in 1993 by the American College of Radiology (ACR) to standardize mammographic reporting, to improve communication, to reduce confusion regarding mammographic findings, to aid research, and to facilitate outcomes monitoring. ${ }^{1}$ According to the Mammography Quality Standards Act (MQSA) of 1997 [Final Rule 62(208):55988], all mammograms in the United States must be reported using one of these assessment categories. ${ }^{1,2}$ Each mammographic study should be assigned a single assessment based on the most concerning findings. ${ }^{1}$

\section{The BI-RADS System}

Table 1 presents BI-RADS classifications and management recommendations as an evidence table. Classifications are divided into an incomplete assessment (category 0) and completed assessments (categories 1, 2, 3, 4, 5, 6). ${ }^{1,3}$ Although there are 7 assessment categories, only 4 outcomes are possible: (1) additional imaging studies, (2) routine interval mammography, (3) short-term follow-up, and (4) biopsy. ${ }^{2}$ All categories reflect the radiologist's level of suspicion for malignancy, and these assessment categories have been shown to be correlated with the likelihood of malignancy. ${ }^{2}$ Because each BI-RADS category has only one specific rec-

Submitted 21 July 2005; accepted 29 July 2005.

From Roswell Park Cancer Institute (MME, SBE, CAC, MCM), Buffalo, NY; and Department of Family Medicine (MME, CHF), State University of New York, Buffalo, NY. Conflict of interest: none declared.

Corresponding author: Margaret M. Eberl, MD, MPH, Roswell Park Cancer Institute, Elm and Carlton Streets, Buffalo, NY 14263 (Margaret.Eberl@RoswellPark.org). ommendation, this system can both inform family physicians about findings and direct appropriate follow-up and management. ${ }^{4}$

The BI-RADS lexicon offers a number of strengths, including the application of a standardized common language to facilitate communication between radiologists, referring physicians, and patients. The system also clarifies the reporting of mammography results and will support the completion of quality improvement activities and clinical research.

The vast majority of screening mammograms are classified as BI-RADS 1 and 2. Between 5\% and $9 \%$ of screening mammograms will require additional follow-up or biopsy including up to $7 \%$ of mammograms classified as BI-RADS category 3 as well as the $2 \%$ of BI-RADS 4 or 5 mammograms. ${ }^{5-7}$ The positive predictive value of a biopsy positive for malignancy increases from $<2 \%$ for BI-RADS category 3 mammograms to $23 \%$ to $30 \%$ for category 4 mammograms and to $95 \%$ for category 5 mammograms. ${ }^{8,9}$ Specific mammographic features with the highest positive predictive value of malignancy include masses with spiculated margins and/or irregular shape, as well as calcifications with linear morphology and/or segmental distribution. $^{10}$

Table 2 summarizes findings from a populationbased mammography registry in New Hampshire showing the proportion of breast cancers observed by BI-RADS category. The rate of breast cancer among women with BI-RADS category 1, 2, or 3 mammograms after 1 year of follow-up was approximately 1/1000 compared with 136/1000 among those with category 4 and 605/1000 with category 5 mammograms. ${ }^{5}$ 
Table 1. Evidence Table for Clinical Management Recommendations for Mammograms by Breast Imaging Reporting and Data System (BI-RADS) Category

\begin{tabular}{|c|c|c|c|c|c|}
\hline $\begin{array}{l}\text { BI-RADS } \\
\text { Category }\end{array}$ & Assessment & $\begin{array}{l}\text { Clinical Management } \\
\text { Recommendation(s) }\end{array}$ & $\begin{array}{c}\text { Strength of } \\
\text { Recommendation }\end{array}$ & References & $\begin{array}{l}\text { Comments on } \\
\text { References }\end{array}$ \\
\hline 0 & Assessment incomplete & $\begin{array}{l}\text { Need to review prior } \\
\text { studies and/or complete } \\
\text { additional imaging }\end{array}$ & A & 3 & $\begin{array}{l}\text { All or none study; consensus } \\
\text { guidelines }\end{array}$ \\
\hline 1 & Negative & Continue routine screening & A & 3,8 & $\begin{array}{l}\text { Consensus guidelines; } \\
\text { validated clinical decision } \\
\text { tool }\end{array}$ \\
\hline 2 & Benign finding & Continue routine screening & A & 3,8 & $\begin{array}{l}\text { Consensus guidelines; } \\
\text { validated clinical decision } \\
\text { tool }\end{array}$ \\
\hline 3 & Probably benign finding & $\begin{array}{l}\text { Short-term follow-up } \\
\text { mammogram at } 6 \\
\text { months, then every } 6 \text { to } \\
12 \text { months for } 1 \text { to } 2 \\
\text { years }\end{array}$ & B & $\begin{array}{l}3,6,8, \\
10-15\end{array}$ & $\begin{array}{l}\text { Consensus guidelines; cohort } \\
\text { studies; large case series; } \\
\text { validated decision tool; less } \\
\text { patient stress; lowered } \\
\text { costs with surveillance }\end{array}$ \\
\hline 4 & Suspicious abnormality & $\begin{array}{l}\text { Perform biopsy, preferably } \\
\text { needle biopsy }\end{array}$ & A & $3,8-10$ & $\begin{array}{l}\text { All or none study; validated } \\
\text { clinical decision tool }\end{array}$ \\
\hline 5 & $\begin{array}{l}\text { Highly suspicious of } \\
\text { malignancy; appropriate } \\
\text { action should be taken. }\end{array}$ & $\begin{array}{l}\text { Biopsy and treatment, as } \\
\text { necessary. }\end{array}$ & A & $3,8-10$ & $\begin{array}{l}\text { All or none study; validated } \\
\text { clinical decision tool }\end{array}$ \\
\hline 6 & $\begin{array}{l}\text { Known biopsy-proven } \\
\text { malignancy, treatment } \\
\text { pending }\end{array}$ & $\begin{array}{l}\text { Assure that treatment is } \\
\text { completed }\end{array}$ & & & \\
\hline
\end{tabular}

\section{Conclusion}

Given that BI-RADS can impact on patient care by minimizing both over-utilization and under-utilization of follow-up tests/procedures, it is critical that family physicians, and other clinicians providing care to women, be familiar with the interpretation of and management strategy for each category.

Primary care physicians would benefit from developing mechanisms, in partnership with their collaborating radiologists, to assure that all women needing further imaging (BI-RADS codes 0 and 3) as well as women with suspicious mammograms (BI-RADS codes 4 and 5) undergo appropriate follow-up. This might include the creation of an office registry to assure optimal management, as well as necessary educational and emotional support.

\section{Clinical Vignettes to Illustrate Clinical Management Using BI-RADS Codes}

Case 1

A 48-year-old female had a screening mammogram showing rounded densities with possible irregular borders amid dense breast tissue bilaterally.

Table 2. Mammography Assessment and Breast Cancers Detected in the New Hampshire Mammography Registry, 11/96 to 10/97, by Breast Imaging Reporting and Data System (BI-RADS) category

\begin{tabular}{|c|c|c|c|c|}
\hline \multirow{2}{*}{$\begin{array}{l}\text { BI-RADS } \\
\text { Category }\end{array}$} & \multicolumn{2}{|c|}{ Baseline Mammography* } & \multirow{2}{*}{$\begin{array}{c}\text { Breast Cancers Detected } \\
\text { Rate/1000 }\end{array}$} & \multirow{2}{*}{$\begin{array}{l}\text { Anticipated Rate of } \\
\text { Malignancy Following Biopsy }\end{array}$} \\
\hline & Number & Percentage & & \\
\hline 1 & 37,995 & $80.65 \%$ & 0.7 & $-\dagger$ \\
\hline 2 & 4,930 & $10.46 \%$ & 1.2 & $-\dagger$ \\
\hline 3 & 3,345 & $7.10 \%$ & 8.1 & $<2 \%^{6-8}$ \\
\hline 4 & 766 & $1.63 \%$ & 135.8 & $23 \%-34 \%^{12-15}$ \\
\hline 5 & 76 & $0.16 \%$ & 605.3 & $\geq 95 \%^{1,4,12-15}$ \\
\hline Total & 47,112 & $100.00 \%$ & & \\
\hline
\end{tabular}

* Data derived from Poplack et. al. ${ }^{5}$

† Categories 1 and 2 are considered to be negative test results. 
Radiologic Interpretation: BI-RADS O (additional imaging needed)

One week later, she had spot compression views that showed the nodules to be regular and sharply defined. Ultrasound examination revealed cysts. Final classification as BI-RADS 2 (benign finding). Patient should continue with routine breast cancer screening.

\section{Case 2}

A 57-year-old female completed a screening mammogram showing calcifications in the right breast. These lesions were confined to the upper outer quadrant but were scattered and round on magnification views. The only prior mammogram was from 4 years ago, was of poor quality, and only showed a few scattered calcifications.

\section{Radiologic Interpretation: BI-RADS 3 (probably benign)}

Despite the lack of a recent prior comparison mammogram, the current calcifications were felt to be of low suspicion. During a discussion the patient was informed that the calcifications were felt to be of low suspicion. A repeat mammography was recommended in 6 months. Follow-up mammogram at 6 months and subsequently at 1 year showed no change in these calcifications.

\section{Case 3}

A 53-year-old female had a screening mammogram that showed linear calcifications clustered tightly in the upper outer quadrant of the right breast. Magnification views confirmed these were clustered and that there was no associated mass. The calcifications were not present on a mammogram obtained 12 months earlier.

\section{Radiologic Interpretation: BI-RADS 4 (suspicious abnormality)}

Results were reviewed with the patient and biopsy was recommended. Vacuum-assisted needle biopsy (Mammotome) was performed using mammographic stereotactic localization. Pathology showed atypical ductal hyperplasia. Subsequent excisional biopsy confirmed the absence of malignancy.

\section{Case 4}

A 62-year-old female completed a screening mammogram showing a $1-\mathrm{cm}$ spiculated mass with as- sociated calcifications lateral to the left nipple area. This lesion was not present on prior mammograms.

\section{Radiologic Interpretation: BI-RADS 5 (bighly suspicious of malignancy)}

Results were reviewed with the patient, and needle biopsy was recommended. Vacuum-assisted needle biopsy (Mammotome) was performed using mammographic stereotactic localization. Pathology showed infiltrating ductal carcinoma, grade II.

\section{Patient Education}

- What is BI-RADS? BI-RADS is a system that was developed by radiologists for reporting mammogram results using a common language. The radiologist assigns a single digit BI-RADS score (ranging from 0 to 5 ) when the report of your mammogram is created.

- What does BI-RADS 0 mean? BI-RADS 0 identifies a mammogram study that is not yet complete. You need to make sure that further evaluation is completed, perhaps extra mammography views or an ultrasound. Further information is needed to make a final assessment (codes 1 to 5 ).

- What does BI-RADS 1 mean? BI-RADS 1 means that the mammogram was negative (ie, no cancer) and that you should continue your routine screening.

- What does BI-RADS 2 mean? BI-RADS 2 also means that your mammogram was normal (ie, no cancer), but other findings (eg, cysts) are described in the report. You should continue your routine screening.

- What does BI-RADS 3 mean? BI-RADS 3 means that your mammogram is probably normal but a repeat mammogram should be completed in 6 months. The chance of breast cancer is approximately $2 \%$ in this category. You should make sure that these follow-up mammograms are completed as requested.

- What does BI-RADS 4 mean? BI-RADS 4 means that the findings on your mammogram are suspicious and that there is approximately a $23 \%$ to $34 \%$ chance that this is breast cancer. You will need a biopsy to get a small tissue sample to make a diagnosis. Talk to your doctors about any questions. 
- What is a biopsy? Biopsy is done to obtain a piece of the breast tissue to determine whether there is cancer. The biopsy may be done using a needle technique (a "needle biopsy") or may require a surgical operation (a "surgical biopsy"). When a needle biopsy is an option, it is usually preferred.

- What does BI-RADS 5 mean? BI-RADS 5 means that your mammogram results are highly suspicious with a $95 \%$ chance of breast cancer. You will need to have a biopsy for diagnosis. Talk to your doctors about what course of action to take.

- What does BI-RADS 6 mean? BI-RADS 6 means that you have already been diagnosed with breast cancer. Discuss your treatment plan with your doctors.

- Why do I need to know my BI-RADS score? Knowing your BI-RADS number can help to make sure that you get proper follow-up after your mammogram. It is a good thing for you to know that score so you can keep track, along with your physician, of what you need to do and actively participate in your medical care.

\section{References}

1. American College of Radiology. The ACR breast imaging reporting and data system (BI-RADS) [web source]. November 11, 2003. Available from: http://www.acr.org/departments/stand_accred/birads/ contents.html. Accessed February, 27, 2004.

2. Liberman L, Menell JH. Breast imaging reporting and data system (BI-RADS). Radiol Clin North Am May 2002;40:409-30.

3. Singletary E, Anderson B, Bevers T, Borgen P, Buys S, Daly M. National comprehensive cancer network: clinical practice guidelines in oncology, breast cancer screening and diagnosis guidelines, v. 1.2003. 08/20/ 02. Available from: http://www.nccn.org/physician_ gls/f_guidelines.html. Accessed March 1, 2004.

4. Bomalaski JJ, Tabano M, Hooper L, Fiorica J. Mam- mography. Curr Opin Obstet Gynecol 2001;13:1523.

5. Poplack SP, Tosteson AN, Grove MR, Wells WA, Carney PA. Mammography in 53,803 women from the New Hampshire mammography network. Radiology 2000;217:832-40.

6. Varas X, Leborgne F, Leborgne JH. Nonpalpable, probably benign lesions: role of follow-up mammography. Radiology 1992;184:409-14.

7. Monticciolo DL, Caplan LS. The American College of Radiology's BI-RADS 3 classification in a nationwide screening program: current assessment and comparison with earlier use. Breast J 2004;10:10610.

8. Lacquement MA, Mitchell D, Hollingsworth AB. Positive predictive value of the Breast Imaging Reporting and Data System. J Am Coll Surg 1999;189: 34-40.

9. Orel SG, Kay N, Reynolds C, Sullivan DC. BIRADS categorization as a predictor of malignancy. Radiology 1999;211:845-50.

10. Liberman L, Abramson AF, Squires FB, Glassman JR, Morris EA, Dershaw DD. The breast imaging reporting and data system: positive predictive value of mammographic features and final assessment categories. AJR Am J Roentgenol 1998;171:35-40.

11. Sickles EA. Management of probably benign breast lesions. Radiol Clin North Am 1995;33:1123-30.

12. Sickles EA, Parker SH. Appropriate role of core breast biopsy in the management of probably benign lesions. Radiology 1993;188:315.

13. Lindfors KK, O'Connor J, Acredolo CR, Liston SE. Short-interval follow-up mammography versus immediate core biopsy of benign breast lesions: assessment of patient stress. AJR Am J Roentgenol 1998; 171:55-8.

14. Brenner RJ, Sickles EA. Surveillance mammography and stereotactic core breast biopsy for probably benign lesions: a cost comparison analysis. Acad Radiol 1997;4:419-25.

15. Sickles EA. Probably benign breast lesions: when should follow-up be recommended and what is the optimal follow-up protocol? Radiology 1999;213: $11-4$. 